\title{
PSYCHIATRIC DISORDERS ASSOCIATED WITH FORCED MIGRATION
}

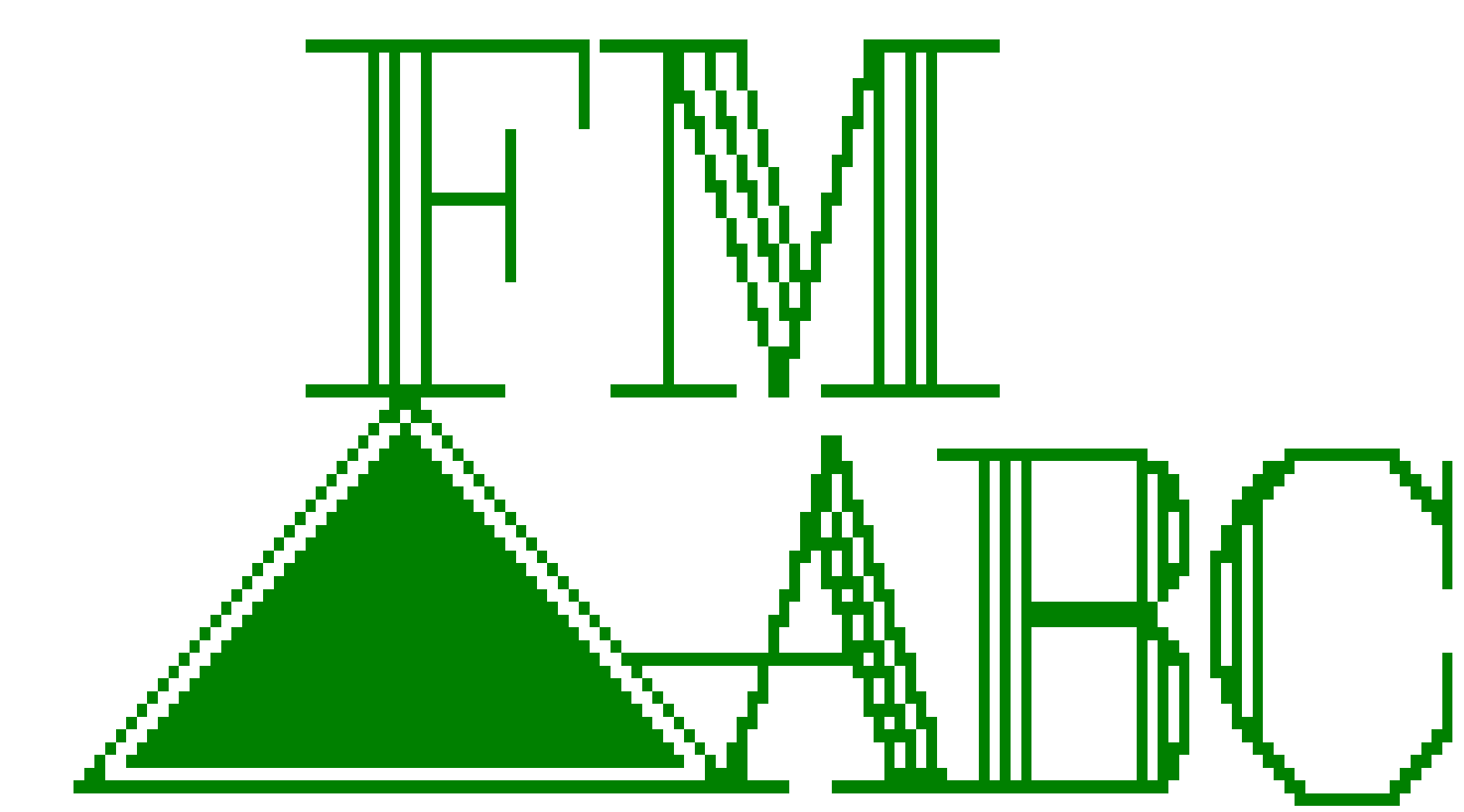

"Ser um imigrante não é deixar a terra é levar a terra consigo" (José Saramago)*

*Being an immigrant is not leaving your homeland, it is taking your homeland within yourself.

CAMPOS, S.B.F.1; TENGUAM,P.T. ${ }^{2}$

Psychiatry Resident from Medical College of $A B C$

MD, Staff Psychiatrist, Department of Psychiatric Emergency Services, Santo André, São Paulo.

\section{CENTER OF MENTAL HEALTH STUDIES FROM ABC}

\section{INTRODUCTION}

Forced migration is a generic term that is used to describe a movement of people in which coercion is observed, including the threat of life subsistence, as well as natural or human causes such as refugees and internally displaced persons, people displaced by natural or environmental disasters, by nuclear or chemical disasters, by hunger or by development projects.

Experiences that lead people of different nationalities to seek refuge from their countries of origin often involve factors with the potential to trigger mental disorders, such as: Depression and Posttraumatic Stress Disorder (PTSD), among others. By the involuntary and sudden character of their displacement, refugees carry with them very little of what had characterized their identity; and these departures are often related to psychological suffering linked to the trauma of which they were subjects in the premigratory and migratory period.

\section{CLINICAL CASE}

M.A.L.M., 43-year-old, female, was born in Porto Principe (Haiti), where she lived for 35 years. At this age, she left to Quito (Ecuador) with the goal of attending college and getting a job. However, the illegal status in Ecuador made it difficult for her to stay and she decided to leave to Brazil along with her husband, her mother and two brothers. M.A.L.M. had her first psychiatric episode in Brazil during her second year in there. In this occasion, she was hyperactive, showed reduced need for sleep, increased psychomotricity, disinhibition and religiously mystical illusions. She was held in the hospital under the care of the psychiatric sector for 36 days and was diagnosed with bipolar affective disorder.

\section{DISCUSSION}

Forced migration is a phenomenon that grows exponentially worldwide mainly due to economic, political, religious and environmental issues. According to data from the National Refugee Council (CONARE, 2016), there were 8863 recognized refugees from 79 different nationalities (28.2\% women) in Brazil in June 2016. The main groups are from Syria (2298), Angola (1420), Colombia (1100), Democratic Republic of Congo (968) and Palestine (376). In 2017, Brazil received 33865 applications for refuge from immigrants according to CONARE. The country with the highest number of requests was Venezuela (17800), followed by Cuba (2373), Haiti (2362), Angola (2036), China (142), Senegal (1221), Syria (823), Nigeria (549), Bangladesh (523), Democratic Republic of Congo (364), Guinea- Bissau (338), Guinea (277), Pakistan (267), and Lebanon (223). There are 3183 other refugees from 14 other nationalities.

\section{NUMBER OF REFUGE REQUESTS}

Número de solicitações de refúgio

$$
\text { por ano }
$$

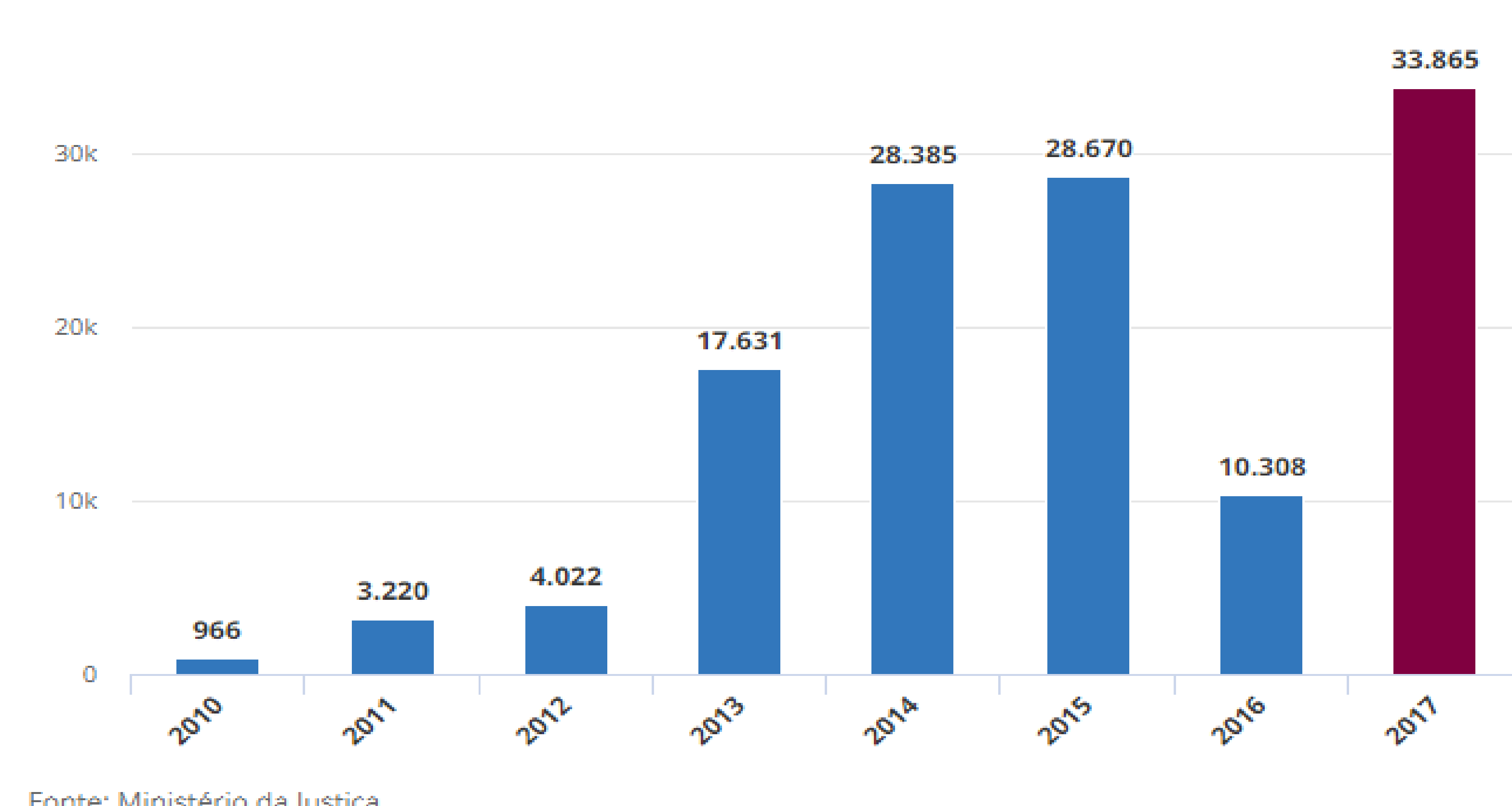

In 2017, there were almost 69 million displaced persons, and more than half of them (52\%) were underaged. In addition, considering the total number of displaced persons, 25.4 million were refugees, 40 million were internally displaced persons and 3.1 million were asylum seekers.

The problems faced by refugees in receiving countries are related to: failing or naccessible health systems, discrimination, lack of food and water, lack of information regarding their rights and duties, unknown language or cultural differences, geographical mobility, separation of family, pressure to send money home. Generally, these difficulties are added to their pre-refuge traumatic experiences, which lead these individuals to a position of extreme social vulnerability and susceptibility to mental health problems.

There is a long-standing inclination of mental health research toward PTSD, depression, and anxiety disorders in settings of complex emergencies. Public mental health research conducted over the past 20 years has largely focused on the immediate psychological aftermaths of armed conflicts in light of the well described associations between these psychiatric disorders displacement, and generalized forms of violence. Demographic and socio-economic characteristics of displaced populations are known to be potent moderators of mental heath: migration, especially internal displacement, protected conflict situations, and economic instability are strongly associated with poor mental health outcomes.

The patient went through situations such as difficulty with the new language, difficulty in finding work, discrimination and financial difficulties. All these factors may have contributed to the onset of psychiatric illness.

It is important to remember that in the case of bipolar affective disorder the genetic factor is very important, however the patient had no family history of the disease. And it is not common to have it at 43 years, like M.A.L.M. The first episode of bipolar affective disorder occurs between 20 and 30 years. Therefore, the environmental factor in this case may have contributed significantly to the development of the clinical condition.

A differential in this case is that bipolar affective disorder is not a psychiatric disorder commonly mentioned in forced migration studies, as post traumatic stress, anxiety and depressive disorders, which shows that other psychiatric comorbidities may also be due to forced migration

Another sensitive issue is that care only occurred in psychiatric emergency criteria from a behavioral disruption, which demonstrates the deficiency of basic health devices in the early detection of these disorders in this population, which shows the need for investments.

\section{CONCLUSION.}

We conclude from the clinical description above that forced migration can bring cerious behavioral complications, triggering unprecedented psychiatric conditions. The first manic episode may also be an important indicator of that

Coordinated assessment programs of mental health should be implemented as well as non-centralized mental health policies and their systematic qualitative evaluations. We understand that emergency sectors should not be the only places of care for this population. It's imperative, given the growing boundaries in the world, the creation of refugee-specific services in which the singularities of language and culture can be valued.

\section{BIBLIOGRAPHIC REFERENCES}

UNHCR). Global trends 2015 [Internet]. Geneva. UNHCR. 2015 [citado 21 Ago 2016]; 68. Disponível em: https://s3.amazonaws.com/unhcrsharedmedia/2016/2016-06-20-global-trends/2016-06-14-GlobalTrends-2015.pdf. [ Links ]

. Did Nov 2016]. Disponivel em: http://www.acnur.org/portugues/recursos/estatisticas/dados-sobre-refugio-no-brasil/. [ Links ] in the United States. JAMA. 2005: 294(5):571-9. DOl: http://dx.doi.org/10.1001/iama.294.5.571. [ Links ]

4. Kolassa IT, Ertt V, Eckart C, Kolassa S, Onyut LP, Elbert T. Spontaneous remission from PTSD depends on the number of traumatic event types experienced. Psychol Trauma. 2010; 2(3):169-74. DOl: http://dx.doi.org/10.1037//a0019362. [ Links ] 5. Martins-Borges L. Migração involuntáría como fator de risco à saúde mental. REMHU. 2013; $21(40): 151-62$. [ Links ]
6 . Amorim P. Mini International Neuropsychiatric Interview (MINI): validação de entrevista breve para diagnóstico de transtornos

mentais
7. Antiss, H., Ziaian, T., Procter, N., \& Warland, J. (2009). Help-seeking for Mental Health Problems in Young Refugees: A Review of the Literature with Implications for
$10.1177 / 1363461509351363$ [Links]

8. Bronstein, l., \& Montgomery, P. (2011). Psychological Distress in Refugee Children: A Systematic Review. Clinical Child Family

Psychology Review, 14, 44-56. doi: 10.1007/s10567-010-0081-0 [ [Links]
9. Buhmann, C. (2014). Traumatized refugees: Morbidity, treatment and predictors of outcome. Danish Medical Journal, 61, 1 29. $[$ Links ]
10. Collins, C.. Z

Zimmerman, C., \& Howard, L. (2011). Refugee, asylum seeker, immigrant women and postnatal depression: rates and risk factors. Archives of Womens Mental Health, 14, 3-11. doi: 10.1007/s00737-010-0198-7 [ [Links ]

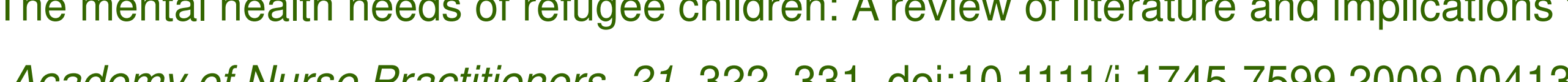

Co 